DOI: $10.1007 /$ s10357-011-2056-4

\section{Naturschutzrechtliches Vorkaufsrecht}

NNatG §29 Abs. 1 und 3, §48

Die Ausübung des naturschutzrechtlichen Vorkaufrechts ist im Verhältnis zu anderen Möglichkeiten eines wirksamen behördlichen Naturschutzes nicht subsidiär.

OVG Lüneburg, Beschluss vom 22. 2.2011 - 4 LA 30/10 -

\section{Aus den Gründen:}

Der Antrag des Klägers auf Zulassung der Berufung gegen das erstinstanzliche Urteil hat keinen Erfolg. Denn die von dem Kläger geltend gemachten Berufungszulassungsgründe des $\$ 124$ Abs. 2 Nr. 1 und 5 VwGO liegen nicht vor bzw. sind nicht hinreichend dargelegt worden.

Aus dem Vorbringen des Klägers zur Begründung seines Zulassungsantrages ergeben sich keine ernstlichen Zweifel an der Richtigkeit des erstinstanzlichen Urteils ( $\$ 124$ Abs. 2 Nr. 1 VwGO).

Denn entgegen der Auffassung des Klägers ist die Ausübung des Vorkaufsrechts durch den Beklagten nach $\$ 48$ NNatG in der hier maßgeblichen, bis zum 28.2.2010 gültig gewesenen Fassung nicht wegen eines Verstoßes gegen den Verhältnismäßigkeitsgrundsatz im Hinblick darauf ermessensfehlerhaft, dass der Beklagte möglicherweise auch durch einen Vertrag mit dem Grundstückseigentümer nach $₫ 29$ Abs. 3 Satz 1 NNatG, ,eine den naturschutzfachlichen Erfordernissen entsprechende Bewirtschaftung der betroffenen Bergwiesen“ hätte erreichen können. Die Ausübung des naturschutzrechtlichen Vorkaufrechts ist nämlich im Verhältnis zu anderen Möglichkeiten eines wirksamen behördlichen Naturschutzes nicht subsidiär (ebenso OVG Magdeburg, Urt. v. 13. 12.2001 - 2 L 342/00; VGH Kassel, Urt. v. 18.1.1996 - 3 UE 2544/93, NVwZ-RR 1996, 500). Dem Verhältnismäßigkeitsgrundsatz wird bei der Ausübung dieses Vorkaufrechts dadurch Rechnung getragen, dass es zum einen nach $\$ 48$ Abs. 3 Satz 2 NNatG nur dann ausgeübt werden darf, wenn das Grundstück für Naturschutz (wie im vorliegenden Fall) und Landschaftspflege oder die Erholung der Allgemeinheit in Natur und Landschaft verwendet werden soll, und dass zum anderen in dem Fall, dass das Grundstück nicht in angemessener Zeit zu diesem, nach $\$ 48$ Abs. 3 Satz 3 NNatG anzugebenden Zweck verwendet wird, der frühere Käufer nach $₫ 48$ Abs. 3 Satz 4 NNatG gegen Erstattung des Kaufpreises dessen Übereignung verlangen kann. Sind die jeweiligen gesetzlichen Voraussetzungen erfüllt, so kann die Behörde daher in der Regel von diesem Vorkaufsrecht ebenso Gebrauch machen wie von der Möglichkeit eines Vertragsschlusses nach $\$ 29$ Abs. 3 Satz 1 NNatG oder einer beispielsweise auf $\$ 29$ Abs. 1 Satz 2 NNatG gestützten Anordnung im Einzelfall, ohne dass sie insofern eine bestimmte Reihenfolge einzuhalten hätte.

Zudem liegt es (auch ohne die von dem Kläger für notwendig gehaltene weitere Aufklärung des Sachverhalts) auf der Hand, dass die durch die Ausübung des Vorkaufsrechts erlangte Eigentümerstellung der Naturschutzbehörde umfassende Möglichkeiten für einen wirksamen Naturschutz eröffnet, die die Naturschutzbehörde in dieser Form durch den vom Kläger als alternative Handlungsmöglichkeit angeführten Vertragsschluss nach $\$ 29$ Abs. 3 Satz 1 NNatG wegen der schwächeren rechtlichen Stellung als bloßer Vertragspartner nicht erlangen könnte. Es handelt sich deshalb insofern regelmäßig nicht um gleichermaßen geeignete Handlungsalternativen. Auch aus diesem Grunde scheidet hier daher eine Verletzung des Verhältnismäßigkeitsgrundsatzes aus.

Die Berufung kann auch nicht wegen des von dem Kläger behaupteten Verfahrensmangels, ,der fehlenden Sachaufklärung" nach $\$ 124$ Abs. 2 Nr. 5 VwGO zugelassen werden.
Denn die von dem Kläger für (weiter) aufklärungsbedürftig gehaltenen Fragen,

„ob der Beklagte ohne Eigentümer zu sein in der Vergangenheit rechtliche Einflussmöglichkeiten hatte, um auf eine bessere Pflege dieser Flächen hinzuwirken und ob er diesen Einfluss tatsächlich ausgeübt hat",

„,welche Auswirkungen der Erwerb der Bergwiesen durch den Kläger auf den Naturschutz hat und welche Vorteile demgegenüber die Ausübung des Vorkaufrechts hätte“,

„,weshalb die Beklagte einerseits in wenigstens 16 anderen Fällen die Belange des Naturschutzes nicht tangiert sieht, wenn die Flächen Dritten zu Eigentum gehören und diese an Landwirte verpachten, eine eben solche Zusammenarbeit mit den Pachtnehmern bei einem Eigentumserwerb des Klägers nicht mehr möglich sein soll“,

„ob Pachtnehmer, die an einer Verlängerung des Pachtverhältnisses interessiert sind, tatsächlich in engerer Form mit dem Beklagten kooperieren",

sind nach dem oben Gesagten nicht entscheidungserheblich gewesen.

Abgesehen davon liegt ein Verstoß gegen die Pflicht zur Sachverhaltsaufklärung nach $\$ 86$ Abs. 1 VwGO regelmäBig dann nicht vor, wenn ein Gericht von einer Beweiserhebung absieht, die ein anwaltlich vertretener Beteiligter weder förmlich beantragt noch in sonstiger Weise angeregt hat (vgl. Senatsbeschlüsse vom 9.2.2010 - 4 LA 186/09und 18.3.2009 - 4 LA 67/09). Hier ergibt sich aus der Niederschrift über die mündliche Verhandlung des Verwaltungsgerichts vom 9.12.2009 nicht, dass der im Termin anwesend gewesene Prozessbevollmächtigte des Klägers einen förmlichen Beweisantrag gestellt oder in sonstiger Weise auf eine weitere Sachverhaltsaufklärung hingewirkt hat. Eine Verletzung des Amtsermittlungsgrundsatzes könnte vor diesem Hintergrund allenfalls dann bejaht werden, wenn sich dem Verwaltungsgericht eine Beweisaufnahme hinsichtlich der oben aufgeführten Fragen hätte aufdrängen müssen, was jedoch zu verneinen ist, da diese Fragen nach dem oben Gesagten nicht entscheidungserheblich gewesen sind. Die sich aufdrängende Notwendigkeit einer weiteren Aufklärung des Sachverhalts hat sich auch nicht daraus ergeben, dass hier nach der Meinung des Klägers ,eine Verletzung des aus Art. 3 GG sich ergebenden Gleichbehandlungsgrundsatzes im Raum" stehen soll, weil der Beklagte in 16 anderen Fällen das Vorkaufrecht nach $\$ 48$ NNatG nicht ausgeübt habe, sondern stattdessen mit den betroffenen Landwirten Pachtverträge unterhalte. Denn die Ausübung des Vorkaufsrechts ist - wie bereits ausgeführt - gegenüber anderen möglichen Maßnahmen eines wirksamen Naturschutzes nicht subsidiär. Im Übrigen ist auf der Grundlage des Vorbringens des Klägers zur Begründung seines Zulassungsantrags nicht ansatzweise ersichtlich, ob insofern, abgesehen davon, dass es sich in diesen Fällen ebenfalls um Landwirte gehandelt haben soll, überhaupt vergleichbare Sachverhalte vorliegen.

Nach allem kommt auch die von dem Kläger als weiterer Verfahrensfehler im Sinne des $₫ 124$ Abs. 2 Nr. 5 VwGO gerügte Verletzung rechtlichen Gehörs wegen der fehlenden Aufklärung der nach seiner Meinung aufklärungsbedürftig gewesenen Fragen von vornherein nicht in Betracht.

\section{Anordnung von Ersatzpflanzungen}

BauGB §34 Abs. 1; NatSchG LSA §39 Abs. 3

Zur Zulässigkeit einer naturschutzrechtlichen Anordnung, Ersatzpflanzungen für beseitigte Obstbäume vorzunehmen.

OVG Magdeburg, Beschluss vom 8. 2.2011 - 2 L 32/10 - 